\title{
Prosodic reading and reading comprehension in university
}

\author{
${ }^{1}$ Aulia Rahmawati, ${ }^{1}$ Ida Rosmalina*, and ${ }^{1}$ Hesti Wahyuni Anggraini \\ English Education Study Program, Universitas Sriwijaya, Indonesia
}

\author{
*Corresponding Author \\ Email: idaroz@yahoo.co.id
}

\begin{abstract}
This study was aimed at investigating the students' English reading comprehension on the basis of the importance of prosodic reading in university level by first, measuring the levels of reading prosody and reading comprehension, characterizing the acoustic characteristics produced by the students, and at last associating the first variable to the second variable. Prosodic reading levels were measured by using Multidimensional Fluency Scale, containing four dimensions. To explore the six types of syntactically complex structures produced by the students orally, this study conducted a descriptive analysis, only focused on some features. The findings showed that the students experienced moderate level of reading prosody and reading comprehension. Also, it could be reported that a significant correlation was found between the two variables. The study reported that prosodic reading contributed to reading comprehension with $r$ obtained .538. A thorough analysis explained that some other related predictors influenced students' comprehension, like difficulties in recognizing the vocabulary, lack of knowledge to review the four types of sentences, and the length of the passage. Among four dimensions, only pace and expression \& volume did contribute to reading comprehension much. Different pause structures produced by the students and the native speakers were clearly identified. This was shown as many students had a long pause and sound hesitate due to their inability to decode the words. Moreover, most of them could not comprehend the sentence structure of the text, when to pause, which words were needed to be stressed, and the intonation used. As a result, they read in a two-three phrases and declined to notice where the endings of sentences and clauses were definitely stated. These results confirmed that pause structure commits as a pivotal factor in determining students' reading comprehension.
\end{abstract}

Keywords: Prosodic reading; Multidimensional Fluency Scale; reading comprehension; acoustic characteristics

Received: Revised: Accepted: Published:

6 August $2019 \quad 27$ January $2020 \quad 27$ February $2020 \quad 29$ February 2020

\section{INTRODUCTION}

Even though reading has been negatively claimed as frustrating experience for most of EFL and ESL students, the ability to read and comprehend the readings is very beneficial. To agree with, reading is viewed as basic life skill 
and a cornerstone for students' success in the college life. It can be said that reading will support the student's ability to gain knowledge from reading materials (Debat, 2006). Similarly, Miller and Schwanenflugel (2009) state that reading is a complex performance which requires implementation simultaneously of multiple interdependent tasks. It means that the readers must not only determine or predict what words are appropriately presented in the text, but he or she must also get the gist of those words. In other words, a reader must derive meaning from what is being read. However, an efficient reading is considered to be a difficult skill to master due to its complex process. It has not been so surprising that ESL and EFL learners deal with various obstacles while reading. Oakhill (as cited in Jayanti, 2016) distinguished three issues in reading comprehension. The first reading issue states that comprehension problems appear as a result of inability to define and interpret at a single-word level. The second reading issue suggests that unskillful reader experience uneasiness towards syntactic and semantic analysis of the text. The third reading issue is that higher order comprehension skills, for instance, making inferences, linking the ideas of the text, and advising comprehension, may be the source of negative experience felt by the students when reading. In fact, Jayanti (2016) who has conducted a study of 80 students found that most of the students find difficulties in reading related to syntactic analysis and semantic analysis.

Reading problems often occur because of students' insufficient understanding of the relationship and functions of words within sentences. In fact, long sentences tend to make the students confused and difficult to convey meaning from the text. Hence, in order to achieve good reading comprehension, the students must learn to integrate the relevant reading tasks all at once, including the ability to process a limited amount of information at a time, it is important for them to be able to automatically decode and understand the text to perform well in higher level processes such as reading comprehension (Binder, Tighe, Jiang, Kaftanski, Qi, \& Ardoin, 2013). Perfetti's, LaBerge and Samuels (as cited in Miller \& Schwanenflugel, 2009) stated that students will engage easily in text-level reading once they can read and process the text fluently and automatically. Presumably, prosodic reading might be included.

Dowhower (1991) stated that reading prosody requires expressive rhythmic and melodic patterns and appropriate prosodic features (simply like pauses, lowering and raising pitch, and lengthening of certain vowel sounds. could be divided into meaningful units. Similarly, Rasinski (2004) conceptualized prosody in reading as a multifactorial concept such as (a) expressiveness, is viewed as the production of reading sounds native-like language, with proper tone and volume; (b) phrasing, is defined as the readers' awareness of phrase groupings, the way how the readers are accustomed to the endings of sentence and clauses, and so on; (c) smoothness, is in accordance with how the readers move the eyes fast and effective slides over the text; (d) and pace, refers to the persistence and rhythm of reading along the text. Furthermore, Kuhn and Stahl (2003) stated that to automatically decoding individual word, prosodic or expressive reading of the text is needed in order for the student to adequately comprehend the text. They theorize that the ability of developing reading prosody may assist 
comprehension because the students are positively believed to group the text in accordance with the major syntactic/semantic elements.

According to Schwanenflugel, Hamilton, Wisenbaker, and Stahl (2009), prosodic reading or expressive reading is commonly interpreted as the high level of the achievement of reading fluency. Thus, prosody must be acknowledged since it has its significant contribution in students' reading fluency, while mostly fluency can be positively seen as prosody as the central part of it. As fluency is a combination of the relevant components of reading, it will facilitate the readers' ability to construct the meaning accurately and meaningfully. Due to the fact that fluency requires obviously reading aloud along with the ability of word recognition, pace, phrase and intonation, silent reading affects in vice versa (Pikulski \& Chard as cited in Kariuki \& Baxter, 2011). It can be said that reading prosody generally represents how to deliver a speech. It is in line with Sinambela (2017) who found that students' reading comprehension and fluency consciously and unconsciously display how prosody runs. When students do not create the reading sounds like natural oral speech, they will sound monotonous, read each word, makes frequent long pauses and sounds tentative, as a result, the reading activity is requiring plenty of time and efforts thus they fail to be able to derive meaning from the text.

Some studies said that one of the indicators of comprehending a reading passage well is prosody. In other words, the better prosodic reading the student is, the better reading fluency the student has. Hence studies conducted by other previous researchers reported that a significant correlation between prosody and comprehension was found in elementary level. Overstreet (2014) examined the effects of the application of prosody as indicated from a study of 20 third-grade students. The application of prosodic reading in EFL class contributed on students' fluency and comprehension. Then, the use of Multi-dimensional Fluency Scale in data collection indicated that overall reading comprehension of 24 students in second grade students in Tennessee is correlated significantly with the use of prosodic oral reading, as found by Kariuki and Baxter (2011).

Other previous related studies in bilingual students or students of English as a second or foreign language showed the significant link between the application of expressive reading and reading comprehension on Cantonese-English bilingual students. Two relevant references reported by Tsui, Tong and Fong $(2016,2018)$ apparently described that CantoneseEnglish bilingual in elementary students who tend to make more pauses in their early English prosodic reading may have worse English reading comprehension skill. This result was supported by another prosodic study of bilingual English-Portuguese conducted by Lopes et al. (2015). They did the study in 98 graders from a private school of North Portugal. The findings resulted that the students' high result of comprehending reading passages was corresponded by an intense use of reading prosody.

The studies executed previously mentioned that although most of the studies in prosody have been conducted with elementary students as their subject, yet many researchers suggest that such kind of reading strategies, the prosodic reading is also applicable and attainable for fluent or skillful readers. Due to the limitations in word recognition, the first thing should be mastered 
by the beginning readers is the attention to the students' background knowledge on word decoding. The statement implied that reading is determined to be faulty and dynamic, as a result, students do not have a fully clear figures of the text (Miller and Schwanenflugel, 2009). It also positively supported that the students' improvements in reading comprehension is tied with the ability to use expressive reading and that the better use of prosodic reading of the students occur hand in hand once decoding becomes prompt (Lopes et al, 2015).

Another argument appears that the decisive point of investigating the positive link of the two variables in skillful readers above can be clearly understood. It assured that they tend to grasp more features of reading prosody than young readers as stated by Breen et al (2016). In line with the evidence before, a study conducted in Medan, Indonesia described that expressive reading was used to evaluate reading fluency of the EFL bachelor's degree students. The participants had been learning English for more than 12 years and were taking informal education. The researcher concluded that one of the valid and reliable indicators of evaluating student's ability in comprehending reading passages was the application of expressive reading and also walks and in hand with the student's reading fluency (Sinambela, 2017).

On the basis of the classroom observation and preliminary interview to the students of the second semester of English Language Education Study Program, FKIP Universitas Sriwijaya, students experienced reading problems to convey meanings of the passages not only because of problems in syntactic analysis and semantic analysis, but also because of their lack of motivation to read. Silent reading made them less motivated and got asleep. This condition was supported by Anggraini (2016). The study reported that only 11 students got high reading comprehension. Some factors affected their reading comprehension, like, lack of motivation to read and their medium level of reading anxiety. That is why it can be believed that prosodic reading may assist the students to comprehend the reading passages. Prosodic reading, in short expressive reading, is expected to encourage them to read more comprehensively as prosodic reading indicates all reading elements (syntactic analysis) and students' reading speed and accuracy (semantic analysis).

Considering that reading subject is one of the mandatory courses that every student must take and since reading courses are pre-requisite, the student must pass the previous subject before they continue to the next course. Therefore, it is urged to identify the student's ability in comprehending reading passages and how their prosodic reading correlates to their reading comprehension score. This research is conducted under the following research questions. They are (1) what is the student's level of prosodic reading?; (2) what is the level of students' reading comprehension?; (3) is there any significant correlation between students' prosodic reading and reading comprehension?; and (4) what are features of prosody mostly produced by the students? The purposes of this study are to investigate (1) the category of students' prosodic reading, (2) the students' level of reading comprehension, (3) the prosodic reading and its correlation with students' reading comprehension, and (4) prosodic reading features produced by the students. 


\section{Prosodic reading}

The combination of expressive rhythmic and melodic patterns is the crucial parts of prosody in reading. This is supported by Schanenflugel et al. (2009) who defined prosody in reading as the blending parts of variety of acoustic property, like duration, frequency, volume, and type of pausing in reading. Similarly, Schreiber (as cited in Miller \& Schwanenflugel, 2009) express that prosody is part of reading fluency, which he described as an expressive and a melody of speech, thus afterward reflects an understanding of the structure and the various rhythm of written language. It is including the variety in intonation, duration, rhythm, and intensity. To simplify these two viewpoints, prosody also known as reading with feeling, in other words, the definition of prosody in reading is as the capacity of how to produce reading aloud that sounds like the common legitimate oral speech (Rasinski, 2004). Dowhower (as cited in Miller \& Schwanenflugel, 2009) characterizes prosodic oral reading as a reader's recognition of identifying appropriate use of pauses, phrasing, pitch, and stress. These components are intended to construct the speech production and communication of meaning in both oral and written language. Moreover, Kuhn, Schwanenflugel, and Meisigner (as cited in Breen et al., 2016) indicate that the properties of prosody in reading, like expression, accent, pausing in reading, rate, and accuracy, are urged to produce the consistency in maintenance of meaning during reading aloud.

Prosodic features such as length, rhythm, accent, and stress that give spoken language its natural rhythm also known as suprasegmental due to their presence above individual segments as Fox (as cited in Goss, 2009) noted that prosody in reading can be constructed within a single word or across an utterance. One thing to consider, in order to create prosodic reading, the reader is really required to have the capability to encounter the uniformity of prosody properties within the rhythmic patterns of language that to some extent cause sensitivity in prosody, that is exactly linked to reading. To consider, Rasinski (2004) described prosodic reading as multidimensional concept as it includes (1) articulation, that refers to reading aloud like natural language with the use of proper volume and tone; (2) phrasing, that defines as the awareness of groupings of utterances, or simply known as the way how and where to start and end reading the sentences, clauses, and even phrases appropriately; (3) smoothness, that goes with how the reader changes, continues reading; and (4) pace, that works with the regularity and rhythm of reading along the passage.

\section{Prosody in reading fluency}

Reading fluency comes across with the link of accuracy, automaticity, and prosody in reading aloud, go together to ease the reader's ability to construct the meaning consistently. One of the indication of the occurrence of oral reading fluency is that the application of prosody correctly, so that the reader comprehends what he or she has already read from the beginning. Therefore, fluency is viewed as a significant pathway to comprehension. According to Rasinski (2004), fluency involves not only speed and accuracy, but also appropriate phrasing, intonation, and expression (prosodic features) to convey meaning and demonstrate understanding, therefore, it seems evident that fluency ties together the sum total of skills necessary for comprehension. 
Schwanenflugel et al. (2009) pointed out that prosody in reading is generally viewed an indicator of achieving fluency in reading. To read prosodically, the reader is really advised to produce so much like a speech, where the effective properties of prosody, like phrasing, stress, patterns, and other common expressions. Theory given by Perfetti in effective verbal speech and specifically, a theory in automaticity by LaBerge and Samuel (as cited in Miller \& Schwanenflugel, 2009) remark that the production of fluent and automatic of a single word permits the resources to be available for the readers to go on into the next processing required for prosody in oral reading. In any case, Kuhn and Stahl (2003) mention that reading fluently includes more than simply reading words promptly and accurately. When an individual read fluently he or she is also reading with expression, incorporating a series of speech features in order to produce the tonal and rhythmic aspects of language.

To sum up, it must be beneficial to take reading fluency into consideration as a link or bond between one major elements of reading comprehension and prosody. To read aloud meaningfully, the reader needs to master prosody. The readers can employ their focus on different tasks or for comprehension. Negative experience while reading might have occurred once the reader thinking about something else, and as a result, not comprehend the passage. This simply can be said that fluency relates straightforwardly to reading comprehension. The application of appropriate phrasing and expression is stressed on the components of prosody in reading. In other words, to prove that the readers are trying to interpret or construct the meaning is that the readers fix all the properties of prosody well and effectively, to be closely sound an authentic oral speech.

\section{Prosodic reading and reading comprehension}

Prosody in reading gives a crucial contribution to students' reading comprehension achievement. Previous relevant studies have persistently reported that prosody in reading text-one major component in reading fluencyand comprehension in reading cannot be separated one to another ((Kuhn \& Stahl, 2003; Miller \& Schwanenflugel, 2009; Veenendaal, Groen \& Verhoeven, 2016). Further, Miller \& Schwanenflugel (2008) stated that the earlier the readers are familiar with prosody in reading, the better they comprehend the reading passages later on. ). Furthermore, Kuhn and Stahl (2003) stated that to automatically decoding individual word, prosodic or expressive reading of the text is needed in order that the student can adequately comprehend the passages. They also agreed that familiarity of prosody in reading may ease the students to comprehend the reading passages because the development of prosodic reading illustrated that the students has already known how to segment the passages or texts on the basis of major syntactic/semantic elements. The capability to use syntactic information to the passages or texts during reading aloud is demonstrated by the effective use of prosodic elements to break the texts into parts, such as the use of major syntactic and semantic elements, besides the retaining the speed and accuracy, appropriate use of prosody, in another hand completes as a figures of suitable parsing of the texts of passages into understandable units ((Miller \& Schwanenflugel, 2009). 
Theoretically, as indicated by Veenendaal et al (2016) there are three possibilities in the directionality of prosody in reading and comprehending reading passages: Unidirectional relations such as (a) prosody in reading a text or passage is viewed as the promotion of reading comprehension. This occurs due to the fact that prosodic oral speech has been appeared to accommodate the readers to categorize sentences or utterances into syntactically and semantically correct blocks, (b) prosody in reading text as a representation of reading comprehension. This viewpoint proposes that the ability to do prosodic reading describes the level of reader's understanding text or passage, and (c) interrelated links between reading prosody and reading comprehension. This view points out on the correlation between the two variables is strong. To simply, the two variables discussed here cannot be broken into one separated tail.

\section{METHOD}

\section{Respondents}

The population of this study was students of English Language Education, FKIP Universitas Sriwijaya. The sample of this study consisted of 77 students in second semester of English Education Study Program of Sriwijaya University. The samples were chosen by using purposive sampling technique. Based on the criteria as follows: (1) the second semester students were considered know how to decode the words well because the development of prosodic reading takes place largely after decoding becomes automatic and (2) they were considered as an adult reader with an average age of 18 years old. Hence, they tend to recognize more properties of prosody than beginning readers.

\section{Instruments}

To measure students' ability in prosodic reading, the students were urged to read the passage orally and their activities were recorded. After that, Multidimensional Fluency Scale by Rasinski (2004) was used to measure the level of student's prosodic reading. The instrument was submitted to a national reading panel in Washington D.C, for validity and highly reliable with test-retest reliability .90. In order to measure students' reading comprehension achievement, the writers delivered the reading comprehension assessment test. Before the reading comprehension assessment was tested to the sample, readability analyses were administered to predict the difficulty level for each passage in the reading test. The result showed that the reading test was appropriate for second semester students. In order to check the content validity, two validators were asked to check the level of appropriateness of each test items. Based on the validators' feedback, those 50 items were appropriate to be tested to university students in the second semester. After that, to have the internal validity the reading comprehension test were tried out to non-sample students with the similar characteristics as the sample students. The result showed that from 50 items, only 30 items were valid. Cronbach's Alpha Reliability Coefficient was measured to determine the reliability of the test. The result showed that the reliability coefficient was 0.850 which indicates that the test was reliable. Therefore, 
there were 30 questions of reading comprehension test which were tested to the sample of this study.

\section{Procedures}

Correlational study was applied due to the fact that it relates two variables as stated by Creswell (2012) and Tuckman (1978). In this study, the two variables were prosodic reading and reading comprehension achievement.

\section{Oral reading fluency assessment}

The calculation of the number of word correct per minute (WCPM) in the production of the fluency of English passages administered during the test of prosodic reading was delivered to confirm the students' connected text reading fluency. Multidimensional Fluency Scale by Rasinski (2004) was used to assess the level of student's prosodic reading. To determine the level of prosodic reading, the students with range scores between 4 and 7 were considered as "low", while students with range score between 8 and 12 were considered as "moderate". Whereas, students with range score between 13 and 16 were considered as "high".

\section{Reading comprehension achievement}

Reading test was administered to measure students' reading comprehension. There were 30 multiple-choice questions with various topics. The students required to answer the questions within the given time.

\section{Data analysis}

In analyzing the data, the summary of calculated data was used to outline the students' scores using descriptive statistics including minimum and maximum scores, means, and standard deviation. The higher the mean score the data were, the higher the level of prosodic reading and reading comprehension achievement the students got. In order to investigate the correlation between criterion and predictor variables, analysis of Pearson Product Moment Correlation Coefficient was applied. Later, simple regression was used to see the contribution of one variable to another variable. Last, multiple regression was used to find out the contribution of each properties of prosodic reading to reading comprehension achievement of the participants.

\section{RESULTS AND DISCUSSION}

\section{The result of prosodic reading (research question 1)}

In order to know the level of prosodic reading, a ready-made passage from the reading comprehension assessment text was distributed to the students. This passage contains 196 words and lasts 1.5 minutes long on average 130 WPM (words per minute). Using Multidimensional Fluency Scale, each rating is applicable for specific behavioral indicators. Each dimension was rated on a 1 (minimum performance) to 4 (maximum performance) point scale. Table 1 shows the descriptive statistic of prosodic reading. 
EduLite Journal of English Education, Literature, and Culture Vol. 5, No. 1, February 2020, pp. 89-108

E-ISSN: 2528-4479, P-ISSN: 2477-5304 http://jurnal.unissula.ac.id/index.php/edulite DOI: http://dx.doi.org/10.30659/e.5.1. 89-108

Table 1. Descriptive statistics of the prosodic reading

\begin{tabular}{llllc}
\hline No. of students & Minimum & Maximum & Mean & Std. Deviation \\
\hline 77 & 5 & 14 & 9.86 & 1.938 \\
\hline
\end{tabular}

Based on the data obtained from the Multidimensional Fluency Scale, students' prosodic reading level ranged from a minimum of 5 to a maximum of 14 with the mean score of 9.86 and a standard deviation of 1.938. To determine the level of prosodic reading, the students with range score between 4-7 were considered as "low", while students with range score between 8-12 were considered as "moderate". Whereas, students with range score between 13-16 were considered as "high". From the data obtained, it can be concluded that, the level of prosodic reading of the overall students is "moderate". See Table 2 below for further information.

Table 2. Students' prosodic reading percentage

\begin{tabular}{lll}
\hline Prosodic Reading Level & Frequency & Percentage (\%) \\
\hline Low (4-7) & 9 & 11.69 \\
\hline Moderate (8-12) & 59 & 76.62 \\
\hline High (13-16) & 9 & 11.69 \\
\hline Total & 77 & 100.00 \\
\hline
\end{tabular}

As shown in Table 2 above, the majority of the students (76.62\%) had moderate level of prosodic reading. While $11.69 \%$ had high level of prosodic reading and another $11.69 \%$ had low level of prosodic reading respectively.

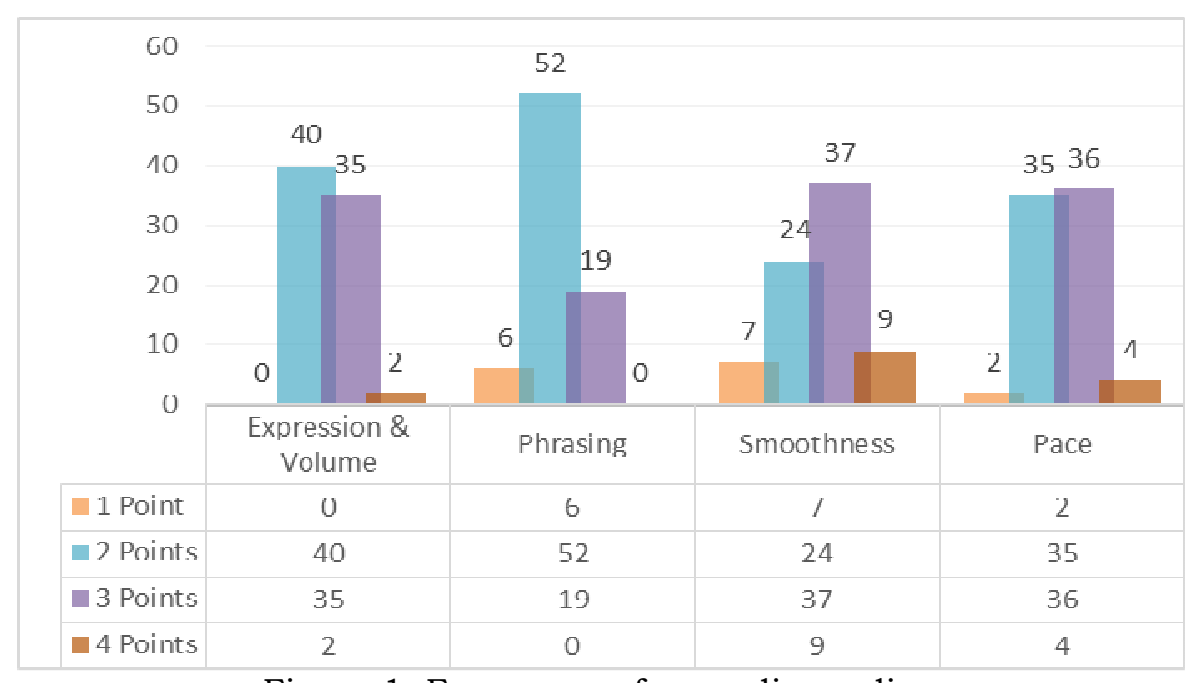

Figure 1. Frequency of prosodic reading

In addition, as shown in figure 2 above, many students got 2 points (the use of some expressions and the reading sound are nearly like native language 
in some areas of the texts. Specifically, in expression and volume, students pay attention consistently on pronouncing every single word and they are eager to read in a low volume). Then, most of the students got 2 points (frequent reading in two-and three-word phrases and mostly giving the reaction of choppy or wavy reading organization; inappropriate use of stress and intonation that lasted on the unsuccessful way to mark or record ends of sentences and clauses) in phrasing. Next, there were 37 students who got 3 points (incidental breaks in smoothness caused by difficulties with specific words and/or structures) in smoothness. Last, there were 36 students who got 3 points (odd bonds of fast and slow reading) in pace.

\section{Result of the reading comprehension test (research question 2)}

In order to know the level of reading comprehension test, reading comprehension test was distributed to students. Firstly, the writers tried out the reading comprehension test to the 40 samples of second semester students in UIN Raden Fatah Palembang. The students had similar characteristics as the sample of this study. The try out result of reading comprehension test was reliable and valid but there were 20 out of the 50 items were considered invalid. The test was in the form of multiple-choice and the total number of the questions was 30 items. The descriptive statistics of the reading comprehension test can be seen in Table 3 below.

Table 3. Descriptive statistics of the reading comprehension test

\begin{tabular}{llllll}
\hline No. of Students & No. of items & Min & Max & Mean & SD \\
\hline 77 & 30 & 30 & 83 & 55.60 & 14.221 \\
\hline
\end{tabular}

Based on the data obtained, students' reading comprehension achievement level were ranged from a minimum score of 30 (failed) to a maximum score of 83 (good) with the mean score of 55.60 and a standard deviation of 14.221. There were 30 items of multiple choice questions and each correct answer was scored 1 while incorrect answer was scored 0 . To determine students' reading comprehension achievement level, students with scores lower than 41 were considered "failed", those who score 41 to 55 were considered "low", those who score 56 to 70 were considered "moderate", those who score 71 to 85 were considered "good", and those who score higher than 85 were considered as "very good. Since the main score of reading comprehension achievement was 55.60, it was concluded that the students' overall reading comprehension achievement score was "moderate".

Table 4. Reading Comprehension Percentage

\begin{tabular}{cccc}
\hline Scoring Range & Category & Frequency & Percentage (\%) \\
\hline $86-100$ & Very Good & 0 & 0 \\
\hline $71-85$ & Good & 11 & 14.28 \\
\hline $56-70$ & Moderate & 25 & 32.47 \\
\hline $41-55$ & Low & 25 & 32.47 \\
\hline $0-40$ & Failed & 16 & 20.78 \\
\hline
\end{tabular}

In addition, Table 4 above showed that there were the same number of students who were categorized as "moderate" and "low" which was $32.47 \%$, 
while $14.28 \%$ were considered "good", and $20.78 \%$ were considered as "failed" in doing the reading comprehension test.

\section{Correlational analysis (research question 3)}

To find out the correlation between the prosodic reading and reading comprehension achievement, the writers did a statistical analysis by using Pearson's Product Moment Coefficient in order to find out the correlation of the two variables. The correlation coefficient is shown in Table 5 below.

Table 5. Correlation of prosodic reading and reading comprehension achievement

\begin{tabular}{|c|c|c|}
\hline Variables & $\begin{array}{c}\mathrm{R} \\
\text { (Pearson Correlation) }\end{array}$ & $\begin{array}{c}\text { p Sig (2-tailed) } \\
(\mathrm{p}<0.05)\end{array}$ \\
\hline c Reading & (1) & 00 \\
\hline
\end{tabular}

As shown in Table 5 above, it was found that the value of r-obtained correlation coefficient of the prosodic reading and reading comprehension achievement was 0.538. The correlation index showed that the correlation direction was positive. To interpret this findings, the value of r-obtained should be consulted to the value r-table. It was found that the r-obtained (0.538) was higher than the value of $r$-table $(\mathrm{df}=(\mathrm{N}-2))(0.224)$. Table 6 also showed that $\mathrm{p}$ value $(0.000)$ was lower than $(0.05)$. It means that $\mathrm{H}_{1}$ was accepted and $\mathrm{H}_{0}$ was rejected. In conclusion, there was a significant correlation between prosodic reading and reading comprehension achievement of English Education Study Program Students of Sriwijaya University.

\section{Regression analysis}

In this study, Simple Linear Regression Analysis was computed in order to find out whether or not there was a significant contribution of prosodic reading to reading comprehension achievement. The result was shown in the following table.

Table 6. Result of regression test

\begin{tabular}{|c|c|c|c|c|}
\hline Model & $\mathbf{R}$ & R Square & Adjusted R Square & Std. Error of the Estimate \\
\hline 1 & $.570^{a}$ & .324 & .287 & 12.000 \\
\hline
\end{tabular}

a. Predictors: (Constant), Pace, Expression_Volume, Smoothness, Phrasing

Table 6 showed that the variables entered were four features of prosodic reading and there were no variable removed. Single step method (enter) was used to see the contribution. The $R$ value was 0.570 . Correlation coefficient ( $R$ value) was calculated to assess the proportion of variability in one variable that can be determined or explained by other variables. Squaring $R$ value leads to $0.570^{2}=0.324$. It means that $32.4 \%$ of prosodic reading contributed to the reading comprehension achievement. 
Table 7. Result of multiple regression test

\begin{tabular}{lllcc}
\hline Model & R & R Square & $\begin{array}{c}\text { R Square } \\
\text { Change }\end{array}$ & $\begin{array}{c}\text { Sig. F } \\
\text { Change }\end{array}$ \\
\hline 1 & $.501^{\mathrm{a}}$ & .251 & .251 & .000 \\
2 & $.560^{\mathrm{b}}$ & .313 & .063 & .011 \\
\end{tabular}

a. Predictors: (Constant), Pace

b. Predictors: (Constant), Pace, Expression_Volume

Moreover, Table 7 showed the results of regression test of prosodic reading features. There were only pace and expression \& volume which were not removed out of four properties of prosody reading available. Phrasing and smoothness were automatically removed by the method because those features were considered not given a significant contribution to the dependent variable. The method used was stepwise. The $\mathrm{R}$ square change value for each feature was $0.251 \%$ for pace and $0.063 \%$ for expression \& volume, which means that $25.1 \%$ of pace and $6.3 \%$ of expression $\&$ volume contributed to the reading comprehension achievement. In addition, the result also showed the regression equation of this study. The equation can be seen from the graph below:

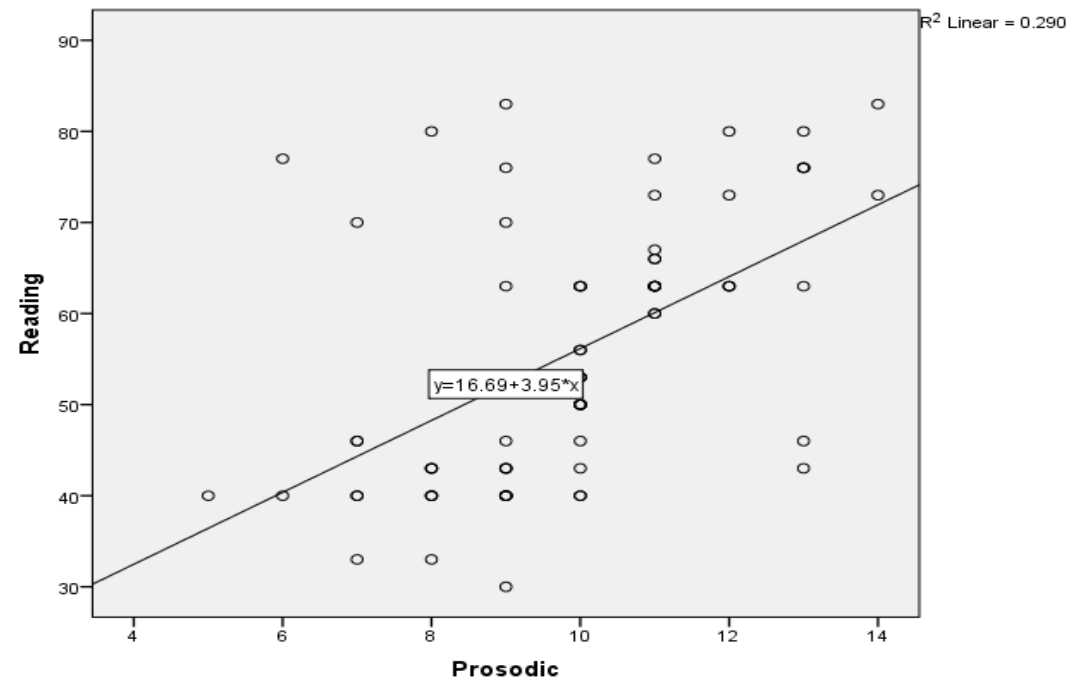

Figure 2. The regression equation graph

Based on the graph above, it can be seen that the regression formula for this correlational study is $\mathrm{y}=16.69+3.95^{*} \mathrm{X}$.

Finally, the result of simple linear regression analysis showed that there was significant contribution of prosodic reading to reading comprehension. It means that the higher students have these skills the higher reading score they will get. In addition, based on the multiple regression analysis using stepwise method, among the four features, only pace and expression \& volume contributed to reading comprehension achievement. Moreover, based on the data, the overall contribution of prosodic reading to reading comprehension 
achievement was $32.4 \%$. Thus, the rest $67.6 \%$ was explained by other predictors. The writers assumed that it might be caused by the prosodic reading passage in this study. Perhaps the reading aloud passage did not engage comprehension processes fully because many participants experienced uneasiness in noticing the vocabularies available in the text or passage, their incapability to construct and understand the sentence structure, and the longer passages appeared. It can be proven in their prosodic reading result; many students had a long pause and sound hesitate due to their inability to decode the words. Moreover, most of them could not comprehend the sentence structure of the text; when to pause in certain sentences, which words need to be stressed, and the intonation used. As a result, they read in a two-three phrases and cannot pinpoint the ends of sentences, clauses, and phrases. Finally, many of them were bored and less motivated because the length of the passage used for prosodic reading test was too long.

\section{Acoustic analysis produced by the students}

Acoustic analysis obtained from each student was applied in order to analyze the properties of prosody in reading that produced by the students. The following six linguistic features were marked for the calculation with reference to properties found in English speaking adults' prosodic reading (Miller and Schwanenflugel, 2009; Schwanenflugel et al, 2004; and Cooper \& Cooper; 1980): (1) basic declarative sentences (draw out pitch decline at the end of the sentence); (2) basic quotatives (draw out short pause following quote); (3) wh questions (may not draw out uprising pitch); (4) yes-no questions (draw out pitch rise); (5) complex adjectival phrase commas (may not draw out pauses); (6) phrase-final commas (may draw out pauses following phrase). However, this study only focused on some features; those are basic declarative sentences, complex adjectival phrase comas and phrase-final commas.

Below are the three samples of students' prosody reading. The discussions include pause, pace, expression and volume, and smoothness.

\section{Student 1 (female student)}

Complementary/ and alternative medicine,/ which includes/ a range of practices/ outside of conventional medicine/ such as herbs,/ homeopathy,/ massage therapy,/ yoga,/ and acupuncture,/ hold increasing appeal for Americans...(1 sec) In fact,/ according to one estimate,/ 42\%/ of Americans have used alternative therapies... (1 sec) In all age groups,/ the use of /unconventional health care" practices" has steadily increased in the last 30 years, / and the trend is likely to continue/, although people born before 1945 are" the least likely" / to turn to these therapies...(1 sec)

Why have so many patients turned to alternative therapies?/ Many are frustrated" by the time constraints of managed care and alienated by conventional medicine's" focus on technology./ Others feel that a holistic approach to health care better reflects" their beliefs and values. Others seek therapies that relieve symptoms associated with chronic disease"/; symptoms / that mainstream medicine cannot treat... (1 sec)

Some alternative therapies have even crossed/ the line/ into mainstream medicine,/ as scientific/...(2 sec) investigation has confirmed..(1 sec) their/ safety" and efficacy. For example/, physicians" may currently prescribe...(1 
sec) acupuncture/ for pain management/ or to control/ the nausea...(1 sec) associated/ with chemotherapy./ Additionally,/ many U.S. medical schools/ teach courses" in alternative therapies/, and many/ health/ insurance companies/ offer some alternative medicine benefits/.

\section{Student 2 (female student)}

Complementary and alternative medicine,/ which includes a range of practices outside of conventional medicine such as herbs,/ home...opathy $(1 \mathrm{sec}) /$, massage... (2 sec) therapy,/ yoga,/ and ... (2 sec) acupuncture,/ hold increasing appeal for Americans./... (2 sec) In fact,/ according to one estimate,/ 42\%" of Americans have used/ alternative therapies./ In all age groups,/ the use of unconventional health/ care practices/ has... (2 sec) steadily increased/ in the last...(1 sec) 30 years,/ and... $(1 \mathrm{sec})$ the trend is likely to continue,/ although people born before 1945" / are the least/ likely to turn to these" therapies./

Why have so many patients turned to alternative therapies? / Many are... (2 sec) frustrated by the time constraints/" of managed care/ and alienated" by conventional medicine's / focus on technology/. Others feel/ that a holistic approach/ to health care better/ reflects/ their beliefs/ and values./...(1 sec) Others seek therapies/ that relieve symptoms/ associated with chronic disease; / symptoms that...(2 sec) mainstream medicine cannot treat./

Some alternative therapies / have" even crossed the line into mainstream medicine,/ as scientific...(2 sec) investigation has confirmed/" their safety" and efficacy"./ For example,/ physicians/ may currently... (2 sec) prescribe... $(2 \mathrm{sec})$

\section{Student 3 (male student)}

Complementary/ and/ alternative medicine,/ which includes a range of/ practices outside /of conventional/ medicine such as/ herbs,/ homeopathy/, massage therapy,/ yoga,/ and/ acupuncture,/ hold/ increasing/ appeal/ for Americans./ "In fact,/ according to one/ estimate,/ 42\% of "Americans have used alternative therapies./" In all age groups,/ the use/ of /unconventional health/ care/ practices/ has/ steadily/ increased/ in/ the last/ 30 years/, and the trend is likely to continue,/ "although people born before 1945 are the least likely" to/ turn/ to/ these therapies./

Why have so many patients turned to alternative therapies? / Many/ are/ frustrated by the time/ constraints/ of managed care/ and/ ... (1 $\mathrm{sec})$ alienated/ by/... (2 sec) conventional/ medicine's focus on technology./ Others/ feel/ that/ a... (1 sec) holistic approach/ to health/ care/ better reflects/ their beliefs/ and values./ Others seek therapies/ that relieve symptoms/ associated with/... (2 sec) chronic disease/; symptoms that mainstream medicine cannot treat./... ( $2 \mathrm{sec})$

Some/ alternative/ therapies/ have even crossed/ the line into mainstream medicine,/ as" scientific investigation has confirmed their/ safety and efficacy"/. For example,/" physicians/ may/ currently/ prescribe/ acupuncture/ for pain management/ or/ to control the/ ... (1 sec) nausea/ associated/ with/... (2 sec) chemotherapy./ Additionally,/ many/ U.S. medical/ schools/ teach/ courses / in alternative therapies, / and many health ... ( $2 \mathrm{sec}$ ) insurance companies/ offer some /alternative medicine benefits./ 
Note: / means phrasing

... means pause

"means pace

Briefly, there are some differences how the three students did prosodic reading, in terms of phasing, pause, and pace.

\section{Discussions}

From the findings above, firstly, the students' level of prosodic reading was moderate. As seen in Figure 1, many students got 2 point score in expression and volume. It means that the students still had limited amount of expressions and they tend to read quietly. However, in phrasing, most of the students got 2 point score which indicated that they read in two or three word phrases and not maintaining to punctuation, stress and intonation. As a result, their readings sound monotonous and thus lead to the impression of choppy word-by-word reading that categorizes into low level readers. However, it seemed that students had a good ability in smoothness. There were 37 students who got 3 point score and 9 students got high score in this feature. In relation to smoothness, the writers observed that even though the good readers read smoothly with some pauses, but they did self-correction when unfamiliar words, sentences or utterances occurred, whereas poor readers or beginning readers struggle and read with extended pauses or hesitation. It was in line with Schwanenflugel et.al (2009) in their research who found that the skilled word decoders read with little pauses between sentences, have a minimal varieties of pause structures, and read with a smoothness and evenness in the way that pauses occurred between sentences. In pace, or as knowns as the ability to read the text with consistent and continuous speed, the writers noticed that most of the students read strange combination of fast and slow throughout reading and some of them were read in a consistently conversational pace. The writers also noted that high speed reading was experienced by good reader while poor readers were struggling and reading each word vigorously. Poor readers might postpone their reading speed due to the fact that they have to show words decoding process and constructing meaning at the same time. Fortunately, for skillful readers, they could automatically invert text to the correct sound and hence allow the occurrence of fast reading speed (Gagen, 2007). Finally, in smoothness and volume most of them read in a low volume and read the sentences less expressively. As a result, their reading comprehension also was low.

The second finding in this study is figuring out the result of students' reading comprehension achievement. Based on the finding, it showed that students' reading comprehension achievement of second semester students was considered as "low" and "moderate". Yet, some students were considered as "good" and some of them still considered as "failed". Furthermore, according to the mean score, the level of students' overall reading comprehension achievement was "moderate" with the main score of 55.60. Moreover, even though the writers created the reading material based on the students' level, it should be noted that many of the students got low score and even failed in the reading comprehension test. This might be occurred because 
of the reading strategy used by the students. Students who are aware of how effective reading strategies are and know well which strategies to use in answering the reading test, tend to be more proficient. This is in line with the study from OECD (2010), which proved that an individual's ability to control his or her comprehension strategies could be robust predictors of reading achievement.

Moreover, the third finding showed that there was a significant correlation between prosodic reading and reading comprehension achievement of second semester students of English Education Study Program of Universitas Sriwijaya with the result of the correlation coefficient of .538 between the two variables. And the data showed that the correlation was positive. The positive correlation means that if one variable increases, the other variable increases as well. In other words, when students' prosodic reading increased, their reading comprehension achievement also increased. The result of the correlation analysis proved that prosodic reading was a factor of students' achievement in reading comprehension. Veenendaal et al. (2016) supported the result of this study. It was found that besides decoding efficiency, reading comprehension contributed to text reading prosody.

Finally, the result of simple linear regression analysis showed that there was significant contribution of prosodic reading to reading comprehension. It means that the higher students have these skills the higher reading score they will get. Simply, students' level of prosodic reading contributed to the students' reading comprehension achievement. In addition, based on the multiple regression analysis using stepwise method, among the four features, only pace and expression \& volume contributed to reading comprehension achievement. Moreover, based on the data, the overall contribution of prosodic reading to reading comprehension achievement was $32.4 \%$. Thus, the rest $67.6 \%$ was explained by other predictors. It might be assumed that it might be caused by the prosodic reading passage in this study. Perhaps the reading aloud passage did not engage comprehension processes fully because many participants experienced uneasiness in noticing the vocabularies available in the text or passage, their incapability to construct and understand the sentence structure, and the longer passages appeared. It can be proven in their prosodic reading result; many students had a long pause and sound hesitate due to their inability to decode the words. Moreover, most of them could not comprehend the sentence structure of the text; when to pause in certain sentences, which words need to be stressed, and the intonation used. As a result, they read in a two-three phrases and cannot pinpoint the ends of sentences, clauses, and phrases. Finally, many of them were bored and less motivated because the length of the passage used for prosodic reading test was too long. It was in line with Schwanenflugel et.al (2009) in their study in which they agreed that using highly decodable passages (or longer passages) tend to be less interesting and demanding on the whole.

Another predictor might have something to do with student's reading strategy. According to Sarris and Dimakos (2015), the more proficient students with the whole-word reading strategy on decoding the reading passages, the more competent the students with letter-sound correspondences, they might move to the beyond expected individual letters. It is supported by Castles and Nation (2006). They stated that familiar words can be determined easily and 
fast if the strategies on whole-word understanding are achieved comprehensively. Therefore, it can be concluded that student's lack of reading strategy was indeed affecting their ability in reading prosodically. The writers also assumed that if students were able to apply reading strategy, they might not have to face difficulties in recognizing the vocabulary and comprehending the sentence structure of the text.

To support the findings, the closer analysis was done to the acoustic analysis of students' prosodic reading. From the sample of Student 1, the basic declarative pause lengths (in second) were determined by watching at the stopwatch visually with the longest pause was 2 sec and the lowest pause was a second. Mostly, Student 1 paused within a second. Thus, it can be assumed that the student was aware of where and when she needed to stop, which words were needed to be stressed, and the intonation used. Comparing to Student 3, pause mostly lasted for 2 second with inconsistent thought group. He did not really comprehend the structure of the stressed due to the fact that he stopped wherever and whenever he planned to stop. Then, the result of prosodic reading Student 2 showed that compared to Student 1, Student 2 did pause longer. However, Student 2 was better in grouping words. Also, the pace done by Student 2 showed the appropriate pace occurred.

For complex adjectival phrases and phrase-final commas, pause duration was measured for each comma; the selection of pause length was from the end of the word preceding the comma to the next word following it. As in Student 1, she knew the structure of the text comprehensively. As a result, she was aware of the thought group, shown in In all age groups,/ the use of / unconventional health care" practices" has steadily increased in the last 30 years,/ and the trend is likely to continue/, although people born before 1945 are" the least likely"/ to turn to these therapies...(1 sec) Then, analyzing the prosodic reading done by Student 3 shown in In all age groups,/ the use/ of /unconventional health/ care/ practices/ has/ steadily/ increased/ in/ the last/ 30 years/, and the trend is likely to continue,/ "although people born before 1945 are the least likely" to/ turn/ to/ these therapies./, it can be said that he read in a two-three phrases wrongly and fail to group where to start and where to end of sentences and clauses. Then, prosodic reading done by Student 2 proved that the importance of good thought group (phrasing), pauses, and pace is in accordance with the ability to understand and comprehend the text or passage well. It can be seen in In all age groups,/ the use of unconventional health/ care practices/ has... (2 sec) steadily increased/ in the last...(1 sec) 30 years,/ and... (1 sec) the trend is likely to continue,/ although people born before 1945"/ are the least/ likely to turn to these" therapies./ Short pause, appropriate pace and effective phrasing determined not only the ability to comprehend the text, but also represent the student's achievement. These findings agreed to the previous study done by Tsui, Tong, and Fung (2016).

\section{CONCLUSION}

Some conclusions were drawn based on the findings and interpretations. First, students considered having moderate level of prosodic reading and among all the four features of prosodic reading, students' were mostly have high scores on smoothness feature. Second, the reading skill of students' as a whole was 
moderate ranging from "low" to "good". Third, there was a significant correlation between the prosodic reading and reading comprehension achievement and the direction was positive. The two variables, prosodic reading and reading comprehension, were shown to have a fair degree of correlation. Fourth, the result of simple regression analysis showed that there was a significant contribution of prosodic reading to student' reading comprehension achievement. Also, it can be concluded that prosodic reading contributes to the reading comprehension. Moreover, among four features, there were only pace and expression \& volume contributed to students' reading comprehension.

\section{ACKNOWLEDGEMENTS}

The writers would like to thank the participants who has helped in data collection. Also, the writers would like state that this research was conducted as a part of requirements of study fulfilment of bachelor's degree of Faculty of Teacher Training of Sriwijaya University.

\section{REFERENCES}

Anggraini, H.W. (2016). Correlational analysis among foreign language anxiety, reading anxiety, and reading achievement of students of Public Health Faculty of Sriwijaya University. The Second Sriwijaya University Learning and Education-International Seminar, 509-522, Retrieved from http://www.conference.unsri.ac.id/index.php/sule/article/view/44/pdf

Binder, S. K., Tighe, E., Jiang, Y., Kaftanski, K., Qi, C., \& Ardoin, P. S. (2013). Reading expressively and understanding thoroughly: An examination of prosody in adults with low literacy skills. NIHMS, 6(8), 665-680. doi: 10.1021/nn300902w.Release

Breen, M., Kaswer, L., Van Dyke, J. A., Krivokapić, J., \& Landi, N. (2016). Imitated prosodic fluency predicts reading comprehension ability in good and poor high school readers. Frontiers in Psychology, 7(JUL). doi:10.3389/fpsyg.2016.01026

Creswell, J. W., (2012). Educational research; planning, conducting and evaluating quantitative and qualitative research. Boston, MA: Pearson Education, Inc.

Debat, E. De. (2006). Applying current approaches to the teaching of reading. English Teaching Forum, 44(1), 8-15. Retrieved from https://eric.ed.gov/?id=EJ1107882

Dowhower, S. L. (1991). Speaking of prosody: Fluency's unattended bedfellow. Theory Into Practice, 30(3), pp. 165-175. doi:10.1080/00405849109543497

Gagen, M. R. (2007). Actual reading errors made by struggling readers. Retrieved from http://www.righttrackreading.com/errors.html 
Goss, S. J. (2009). Prosody and reading comprehension in L2 Japanese (Doctoral dissertation, The Ohio State University, United States). Retrieved from: https://etd.ohiolink.edu/rws_etd/document/get/osu 1250603347/inline

Jayanti, F. G. (2016). Reading difficulties: comparison on students and teachers perception. Fourth International Seminar on English Language and Teaching, 296-301. Retrieved from ejournal.unp.ac.id/index.php/selt/article/view/6939

Kariuki, P., \& Baxter, A. (2011). The relationship between prosodic oral reading assessments and standards-based reading assessment in a 2nd grade classroom. Conference of the Mid-South Educational Research Association Oxford, Mississippi. Retrieved from: https://eric.ed.gov/?id=ED526238

Kuhn, M. R., \& Stahl, S. A. (2003). Fluency: A review of developmental and remedial practices. Journal of Educational Psychology, 95(1), 3-21. doi:10.1037/0022-0663.95.1.3

Lopes, J., Silva, M. M., Moniz, A., Spear-Swerling, L., \& Zibulsky, J. (2015). Prosody growth and reading comprehension: a longitudinal study from 2nd through the end of 3rd grade. Revista de Psicodidactica, 20(1), 5-23. doi: $10.1387 /$ RevPsicodidact.11196

Miller, J., \& Schwanenflugel, P. J. (2009). Prosody of syntactically complex sentences in the oral reading of young children, 98(4), 839-843. doi:10.1037/0022-0663.98.4.839.Prosody

OECD. (2010). PISA 2009 result volume iii : Learning to learn -student engagement, strategies, and pratices policies and practices for successful schools.

Overstreet, T. B. (2014). The effect of prosody instruction on reading fluency and comprehension among third-grade students. (Doctoral dissertations, Andrews University). Retrieved from: http://digitalcommons.andrews.edu/dissertations / 616

Rasinski, T. V. (2004). Assessing Reading Fluency. Pacific Resources for Education and Learning (PREL), 28. doi: 10.1007/s11881-010-0039-4

Schwanenflugel, P. J., Hamilton, A. M., Wisenbaker, J. M., \& Stahl, S. A. (2009). Becoming a fluent reader: reading skill and prosodic features in the oral reading of young readers Paula, 96(1), 119-129. doi: 10.1037/00220663.96.1.119.Becoming

Sinambela, S. E. (2017). Prosody as a tool for assessing reading fluency of adult ESL students, 8(6). doi: 10.7575/aiac.alls.v.8n.6p.83

Tsui, R. K., Tong, X., \& Fung, L. S. (2016). The role of prosodic reading in english reading comprehension among Cantonese-English bilingual children. Proceedings of the 8th International Conference on Speech Prosody (SP2016), (October), 582-586. doi: 10.21437/SpeechProsody.2016-119 
Tuckman, B. W. (1978). Conducting educational research (2nd ed.). San Diego, CA: Harcourt Brace Jovanovich, Inc.

Veenendaal, N. J., Groen, M. A., \& Verhoeven, L. (2016). Bidirectional relations between text reading prosody and reading comprehension in the upper primary school grades: A longitudinal perspective. Scientific Studies of Reading, 20(3), 189-202. doi: 10.1080/10888438.2015.1128939

Xiuli Tong, S., Ka-Ying Tsui, R., \& Kan-Ki Fung, A. (2018). Prosodic reading and reading comprehension in Chinese and English among Hong Kong Cantonese-English bilingual children: A longitudinal study, (June), 858862. doi: 10.21437/SpeechProsody.2018-173. 